\title{
Secondary 1 Training Program of the Project P.A.T.H.S. in Hong Kong: an evaluation based on program participants
}

\author{
Ben M.F. Law ${ }^{1, *}$ and Daniel T.L. Shek ${ }^{2-5}$ \\ ${ }^{1}$ Department of Social Work and Social Administration, \\ The University of Hong Kong, Hong Kong, P.R. China \\ ${ }^{2}$ Department of Applied Social Sciences, The Hong Kong \\ Polytechnic University, Hong Kong, P.R. China \\ ${ }^{3}$ Public Policy Research Institute, The Hong Kong \\ Polytechnic University, Hong Kong, P.R. China \\ ${ }^{4}$ Kiang Wu Nursing College of Macau, Macau, P.R. China \\ ${ }^{5}$ Division of Adolescent Medicine, Department of \\ Pediatrics, Kentucky Children's Hospital, University of \\ Kentucky College of Medicine, Lexington, KY, USA
}

\begin{abstract}
A total of 1744 participants comprising 44 groups participated in a 3-day Secondary 1 Training Program of Project P.A.T.H.S. in Hong Kong. At the end of the training program, the participants were invited to respond to a subjective outcome evaluation. Results showed that the assessment tools are internally consistent. Descriptive statistics revealed that evaluations of the respondents are positive in terms of the training program content, interaction, trainers' performance, self-performance, administrative arrangement, and overall satisfaction. Overall satisfaction was predicted by training content, trainers' performance, self-performance, and interaction. Training content and trainers' performance explain half of the total variance. The present findings reiterate other studies regarding the effectiveness of the training program of Project P.A.T.H.S. in promoting the participants' knowledge, attitude, and skills in delivering the program.
\end{abstract}

Keywords: Chinese adolescents; Project P.A.T.H.S.; subjective outcome evaluation; training.

\section{Introduction}

To promote holistic development of adolescents in Hong Kong (1), the Hong Kong Jockey Club Charities Trust approved an earmarked grant of HK\$750 million (HK\$400 million for the first cycle and HK\$350 million for the second cycle) to support the development, implementation, and

*Corresponding author: Professor Ben M.F. Law, Department of Social Work and Social Administration, The University of Hong Kong, Hong Kong, P.R. China

E-mail: blaw@hku.hk

Submitted October 2, 2010. Revised November 24, 2010. Accepted December 2, 2010. Previously published online June 27, 2011. evaluation of a positive youth development project in Hong Kong in 2005 (2). This project, called Project P.A.T.H.S., has two tiers of programs. The Tier 1 Program is a universal positive youth development program where Secondary 1 (Grade 7) to Secondary 3 (Grade 9) students participate for an academic year.

The Tier 1 Program is a comprehensive positive youth development program that focuses on social and emotional competencies in adolescents (3). It attempts to help participants acquire skills to recognize and manage emotions, develop caring and concern for others, make responsible decisions, establish positive relationships, and face challenging situations effectively via curriculum-based programs implemented in the school context. Project P.A.T.H.S. aims to develop 15 positive youth development constructs: bonding, social competence, emotional competence, cognitive competence, behavioral competence, moral competence, self-efficacy, prosocial norms, resilience, selfdetermination, spirituality, belief in the future, clear and positive identity, prosocial involvement, and recognition for positive behavior (4). Various teaching units are developed under each positive youth construct. The teaching unit and the related lesson plan do not adopt a one-way pedagogical lecture; rather, a multimodal teaching approach is adopted, including structured exercises, games, role plays, video clips, and discussions. Students learn the importance of the youth constructs primarily through different forms of activities and experiential learning.

In the Tier 1 Program, the potential program implementers (PPIs) are typically teachers or social workers who are required to attend a 20 -h training program for a particular grade before they can conduct the programs to students at schools. The training program of Project P.A.T.H.S. has six general objectives: (a) to understand the nature of adolescent development and to cultivate positive attitudes towards adolescent development; (b) to understand the nature of positive youth development; (c) to familiarize participants with the nature of Project P.A.T.H.S.; (d) to understand the content of the Tier 1 Program; (e) to acquire the attitude, knowledge, and skills conducive to successful implementation of the program; and (f) to establish a self-help support network among the participants. The Secondary 1 Training Program is an introductory training program that attempts to familiarize its participants with the background rationales, program design, teaching methodology, and evaluation strategies of Project P.A.T.H.S.

Systemic training is an important component in the Project P.A.T.H.S. The training workshops, such as the Tier 1 Program, adopt various formats, including video clips, structured role plays, discussions, mini-lectures, and games. Many 
PPIs join the workshop because they want to be well prepared to deliver the program. Therefore, many exercises from the real Tier 1 Program are used to provide PPIs with first-hand experience of the effect of the activities. Through interactive and experiential training, PPIs come to understand how to deliver effective programs to adolescents.

Evaluation studies of the training programs are necessary for PPIs. The evaluation aims at addressing the effectiveness of the training programs and at further improving the quality of existing training material and delivery methods. However, a review of the literature shows a significant knowledge gap (5). Obviously, one of the most direct ways to evaluate data is to understand the subjective views of the program participants (i.e., client satisfaction approach).

Against this background, this paper documents the evaluation findings related to 44 training workshops carried out during the Full Implementation Phase of the Project P.A.T.H.S. for the Secondary 1 (Grade 7) training from school year 2006 to 2009. Subjective outcome evaluation or client satisfaction survey, a common evaluation strategy in human services, was the primary evaluation strategy used in this study. According to the Joint Committee on Standards for Educational Evaluation (6), stakeholders should be identified (Standard U1), and their views should be taken into account (Standard F2). According to utilization-focused evaluation (7), relevant stakeholders should also be involved in the evaluation process. By adopting a constructivist paradigm in social sciences (8), the perceptions of the participants "from the inside" could be captured. Their voices can be heard and the researchers could be attuned to the participants' subjective experience. The researchers should not impose their assumptions upon the participants.

The training for the Full Implementation Phase of Project P.A.T.H.S. was carried out during the school years of 20062009. More than 1700 individuals participated in the training workshops. Several aspects of the evaluation deserve attention. First, the participants were asked to evaluate the training content, including its relevance towards understanding the training programs and adolescent development. Second, the participants were asked to evaluate the outcome of the training, such as expansion of the support network among the program participants and satisfaction from peer interaction and instructor-participant interaction. Third, the participants were asked to evaluate the performance of the instructors, including mastery of the curriculum, understanding the needs of the participants, and conducting a good training. Fourth, the participants were asked to evaluate whether their level of satisfaction with regard to their performance during the training process. Fifth, the participants were asked to evaluate the administrative arrangements, such as the workshop facilities and the relevant information provided prior to the workshop. Finally, both quantitative and qualitative data were collected for the related subjective outcome evaluation in the training workshops.

Quantitative data can summarize the profiles of the respondents; thus, this paper focuses on the quantitative data collected in the subjective outcome evaluation. The study attempts to address two questions: 1) "What is the perception of the program participants of the training content, interaction, instructor performance, self-evaluation, and administrative arrangement, as well as their overall satisfaction of the training program?" and 2) "What are the predictors of subjective outcome evaluation based on the perspective of the program participants?"

\section{Methods}

\section{Participants and procedure}

In the Full Implementation Phase, 44 training groups involving 1744 participants were conducted. In the last session of the 20-h training program, the participants were invited to anonymously rate the program in terms of four instruments.

According to the anonymous survey, participants consisted of 521 males (29.9\%) and 1222 females (70.1\%); one participant did not disclose his or her gender. These participants consisted of 1315 teachers $(75.4 \%)$ and 414 social workers $(23.7 \%)$, with 15 participants coming from other disciplines such as teaching assistants or program workers. The mean years of job experience working with youths was 10.6 years $(\mathrm{SD}=8.29)$.

\section{Instruments}

\section{Participants' Perception of Training Program (PROGRAM)}

The 16-item scale includes items such as "It has strengthened me to understand the content of the Tier 1 Program" and "It has promoted self-reflection." Responses were made on a 6-point Likert scale [strongly disagree (1) to strongly agree (6)]. For example, Items 11 and 14 represent client satisfaction and perceived satisfaction of other participants. The mean score reveals the satisfaction level (SATISFY) of the participants.

For the rest of the items, principal component analysis with varimax rotation was performed so that the data could be reduced to meaningful factors. A two-factor solution explaining $62.89 \%$ variance was found. The eigenvalues of these two factors were greater than unity. The resulting scree plot of the eigenvalues revealed that the leveling off to a straight horizontal line occurred after the second eigenvalue, further suggesting the presence of two factors. Table 1 shows these results. The first factor was found to be "training content" (CONTENT), which included understanding adolescent development and using the program materials. The second factor was found to be "interaction" (INTERACT), which included networking, peer interaction, and instructor-PPI interaction. The internal consistency of the CONTENT subscale, in terms of Cronbach's $\alpha$, was found to be 0.84 . The internal consistency of INTERACT subscale was found to be 0.70 . The internal consistency of the overall scale was found to be 0.94 , which was very satisfactory.

\section{Participants' Perception of Instructor (INSTRUCTOR)}

This 5-item scale includes the evaluation of instructor in terms of understanding of the course, teaching skills, and professional attitudes. Responses were made on a 6-point Likert scale [strongly disagree (1) to strongly agree (6)]. The internal consistency of the scale was found to be 0.94 , which was very satisfactory. 
Table 1 Participants' Perception of Training Program (PROGRAM) scale (principal components analysis, varimax rotation).

\begin{tabular}{lll}
\hline Factor & Content & Interact \\
\hline Variance explained & $55.02 \%$ \\
1. It has strengthened my understanding of the nature of adolescent development. & $\mathbf{0 . 7 0}$ \\
2. It has helped me cultivate a positive attitude towards adolescent development. & $\mathbf{0 . 6 9}$ & 0.29 \\
3. It has strengthened my understanding of positive youth development, including its concept, & $\mathbf{0 . 7 9}$ \\
design, and research. & $\mathbf{0 . 8 0}$ \\
4. It has helped me understand the Project P.A.T.H.S., including its basic philosophy, design, & 0.31 \\
implementation, and evaluation. & $\mathbf{0 . 8 1}$ \\
5. It has strengthened me understand the content of the Tier 1 Program. & $\mathbf{0 . 7 9}$ \\
6. It has helped me acquire the attitude, knowledge, and skills conducive to the successful & 0.16 \\
implementation of the Tier 1 Program. & \\
7. It has helped me establish a self-help support network and share teaching experiences & $\mathbf{0 . 6 3}$ \\
among the program participants. & $\mathbf{0 . 5 5}$ \\
8. The training methods and activities are appropriate (e.g., lecture, games, group discussion). & 0.13 \\
9. Training time is appropriate. & $\mathbf{0 . 7 7}$ \\
10. Training content has met my expectation. & 0.15 \\
12. There was much peer interaction among participants. & 0.42 \\
13. Instructor(s) encouraged participants to do their best. & $\mathbf{0 . 6 2}$ \\
15. It has promoted self-reflection. & $\mathbf{0 . 6 3}$ \\
16. It has helped me recognize factors affect teaching. &
\end{tabular}

atems 11 and 14 are the overall satisfaction towards the program and are removed for the principal components analysis. Factor loading $>0.50$ are in bold.

\section{Participants' Perception of their own Performance (SELF)}

This 4-item scale measures the participants' self-perceived performance at the training. It included program involvement and learning application. Responses were made on a 6-point Likert scale [strongly disagree (1) to strongly agree (6)]. The internal consistency of the scale was found to be 0.81 , which was satisfactory.

\section{Participants' Perception of Administrative Arrangement (ADMIN)}

This 6-item scale measures the perception of the participants regarding the administrative arrangement, including program enrolment, hospitality, venue, and facilities. Responses were made on a 6-point Likert scale [strongly disagree (1) to strongly agree (6)]. The internal consistency of the scale was found to be 0.80 , which was satisfactory.

\section{Results}

For a 6-point scale, the ratings of the subjective evaluation were very positive (Table 2). The highest was for the training content (mean=5.81, $\mathrm{SD}=0.76$ ) and instructor performance (mean=5.17, $\mathrm{SD}=0.82$ ). The lowest was in self-evaluation (mean=4.76, $\mathrm{SD}=0.58$ ), which was still high. The overall satisfaction was also high (mean=4.78, $\mathrm{SD}=0.99$ ).

Table 3 shows the intercorrelation table of all indicators of the subjective outcome evaluation. All measures were found to be intercorrelated. The CONTENT and INSTRUCTOR measures had the highest correlation with the overall satisfaction (SATISFY). The variable with the lowest correlation with the satisfaction was administrative arrangement (ADMIN).

Because the variables were all related to the overall satisfaction, these four predictors (INTERACT, INSTRUCTOR,
Table 2 Descriptive statistics of the variables related to subjective evaluation.

\begin{tabular}{llll}
\hline Variables & $\mathrm{n}$ & Mean & $\mathrm{SD}$ \\
\hline INTERACT & 1740 & 4.99 & 0.62 \\
SATISFY & 1740 & 4.78 & 0.99 \\
INSTRUCTOR & 1739 & 5.17 & 0.82 \\
SELF & 1743 & 4.76 & 0.58 \\
ADMIN & 1742 & 4.95 & 0.52 \\
CONTENT & 1744 & 5.81 & 0.76 \\
\hline
\end{tabular}

SELF, ADMIN) were used to predict the participants' satisfaction. Table 4 shows the results of multiple regression analysis. The magnitude of prediction $\mathrm{R}^{2}$ was found to be 0.82 . The effect size, Cohen $\mathrm{f}^{2}$, was found to be 4.56 , which was rather large. In comparing the standardized regression coefficients, the significant predictors included were CONTENT, INSTRUCTOR, SELF, and INTERACT. The two largest predictors were CONTENT $(\beta=0.63)$ and INSTRUCTOR $(\beta=0.27)$. The squared partial correlation for CONTENT was 0.34 , whereas that for INSTRUCTOR was 0.17 . These two variables explained more than half of the total variance.

\section{Discussion}

The subjective outcome evaluations based on the responses of the PPIs in the Project P.A.T.H.S. are presented in this study. There are several guiding principles in the design of the training programs: (a) designing the training program around an experiential learning model; (b) impartation of knowledge; (c) provision of demonstrations; (d) raising participants' motivation; (e) promotion of teaching self-efficacy, self-reflective skills, and open-mindedness; and (f) promotion 
Table 3 Intercorrelation among all the variables related to subjective evaluation.

\begin{tabular}{llllll}
\hline & INTERACT & INSTRUCTOR & SELF & ADMIN & CONTENT \\
\hline SATISFY & $0.63^{* * *}$ & $0.80^{* * *}$ & $0.63^{* * *}$ & $0.43^{* * *}$ & $0.89^{* * * *}$ \\
INTERACT & & $0.60^{* * *}$ & $0.54^{* * *}$ & $0.41^{* * *}$ & $0.65^{* * *}$ \\
INSTRUCTOR & & $0.57^{* * *}$ & $0.34^{* * *}$ & $0.78^{* * *}$ \\
SELF & & & $0.43^{* * *}$ & $0.55^{* * *}$ \\
ADMIN & & & & $0.39^{* * *}$ \\
\hline
\end{tabular}

$* * * \mathrm{p}<0.001$.

of active participation and open discussion. Furthermore, the objectives, theoretical framework, and activities of each session were clearly stated by the instructors at the beginning of the session. These principles are well adopted in the training program (5).

The present quantitative findings show that the participants in general were very positive towards the training program. The training content, interaction from the training, instructor's performance, self-perceived performance, and administrative arrangement were associated with the global satisfaction of the participants. Most of the participants felt that they were competent to deliver the programs in the future. Such selfefficacious beliefs are important for their job satisfaction and program delivery quality $(9,10)$. Together with other evidence (11-16), the project can be deemed to be successfully carried out, with significant impact on program implementers and students.

The training content of Project P.A.T.H.S. involves two main aspects. The first aspect is the understanding of psychosocial development of adolescents in Hong Kong. The second aspect is the understanding of the Tier 1 materials so that the workers are well prepared for the activities. Both are important for client satisfaction, which is the main reason why the workers join the workshop. In addition, the training also aims to facilitate the mutual help network among workers responsible for implementing the Tier 1 Program. The interactions among members and with the instructor are crucial for selfreflection and social learning. Self-reflection is conducive to learning outcomes $(17,18)$. The instructor is evaluated in terms of his or her knowledge, attitudes as a good teacher of positive youth development, and specific skills related to the Tier 1 program implementation. The evaluation of self-performance is equally important. For a 3-day interactive workshop, self-disclosure is expected to increase. Self-disclosure is correlated with the positive perception of the program (19,

Table 4 Regression analysis and squared semipartial correlation of participants' satisfaction.

\begin{tabular}{lrllcl}
\hline Variables & \multicolumn{1}{c}{$\mathrm{b}$} & $\mathrm{SE}$ & $\beta$ & $\mathrm{t}$ & $\mathrm{SR}^{2}$ \\
\hline Constant & -3.35 & 0.11 & & $-29.32^{* * *}$ & \\
INTERACT & 0.05 & 0.02 & 0.03 & $2.23^{*}$ & 0.02 \\
INSTRUCTOR & 0.32 & 0.02 & 0.27 & $16.23^{* * *}$ & 0.17 \\
SELF & 0.06 & 0.02 & 0.04 & $2.69^{* *}$ & 0.03 \\
ADMIN & 0.05 & 0.02 & 0.02 & 1.92 & 0.02 \\
CONTENT & 0.98 & 0.03 & 0.63 & $33.51^{* * *}$ & 0.34 \\
\hline
\end{tabular}

$* * * \mathrm{p}<0.001 ; * * \mathrm{p}<0.01 ; * \mathrm{p}<0.05$.
20). The administrative arrangement refers to the venue, facilities, and information received before the workshop.

The present findings show that training content, the instructor, interaction, and self-performance could predict the overall satisfaction of the participants. The training content and the instructor can explain half of the total variance. A wellestablished training program; an instructor who can deliver skills, attitudes, and knowledge; self-motivated involvement; and good interaction between other people are all significant elements for a successful training workshop. Arguably, the effectiveness and positive evaluation findings associated with Project P.A.T.H.S. are partly the result of the quality training program for the PPIs. Shek and Sun advocate the five "Ps" in the success of positive youth programs (21): Program, People, Process, Policy, and Place. This study has shown that the training program also requires the input of "Program" (content), "People" (trainers), and "Process" (interaction among participants and with the trainer). The administrative management is not significant in the prediction of participant satisfaction; thus, this could be a distal factor affecting satisfaction. If administrative arrangement is not rendered properly, the general perception of other training components would be severely affected. This factor serves as a "hygiene factor" (22) and it is the prerequisite of quality training. It could be the moderator between the components and participant satisfaction. Further research should explore this matter to bring conceptual clarity.

Although utilization of subjective outcome evaluation has been criticized as biased and unable to reflect the real behavioral changes in the program participants, this study possesses several strengths. First, this study is one of the earliest empirical studies on the training of PPIs in a positive youth development program in Chinese communities. Second, a respectable sample size is used in the study. Third, this study investigates different aspects of subjective outcomes, including views on the program, instructors, self-performance, and overall satisfaction, and all these scales were found to be reliable. The adoption of psychometrically sound measures is a significant contribution to the literature.

This study also has two limitations. First, the present findings are based on quantitative data. Further integration of the present findings with qualitative evidence is desirable. Second, there are two alternative explanations for the present positive outcomes. One, the participants could have given positive evaluations because of demand characteristics (i.e., they consciously acted in a favorable manner). They could have considered the experience as on-the-job 
training for a future profession; thus, they would exert greater effort to perform well. By contrast, most participants are aware that they would have to deliver the Tier 1 Program in the future. Because they would have to deliver the program, they would tend to look at the positive effects of the program; otherwise, cognitive dissonance and internal struggles would occur (23). These two explanations should be incorporated in the future subjective evaluation design. Despite these limitations, the present findings are pioneering additions to the Chinese database on positive youth development. They are also consistent with the quantitative and qualitative evaluation findings previously reported in the literature (24-28).

\section{Acknowledgements}

The preparation for this paper and the Project P.A.T.H.S. are financially supported by the Hong Kong Jockey Club Charities Trust.

\section{References}

1. Shek DTL. Conceptual framework underlying the development of a positive youth development program in Hong Kong. Int $\mathrm{J}$ Adolesc Med Health 2006;18:303-14.

2. Shek DTL, Sun RCF. Development, implementation and evaluation of a holistic positive youth development program: project P.A.T.H.S. in Hong Kong. Int J Disabil Hum Dev 2009; 8:107-17.

3. Collaborative for Academic, Social, and Emotional Learning. Available at: http://www.casel.org/.

4. Shek DTL. Construction of a positive youth development program in Hong Kong. Int J Adolesc Med Health 2006;18:299-302.

5. Shek DTL, Wai CLY. Training workers implementing adolescent prevention and positive youth development programs: what have we learned from the literature? Adolesc 2008;43:823-45.

6. Royse D. Research methods in social work. Pacific Grove, CA: Brooks/Cole, 2004.

7. Patton MQ. Utilization-focused evaluation: the new century text. Thousand Oaks, CA: Sage, 1997.

8. Miles MB, Huberman AM. Qualitative data analysis. Thousand Oaks, CA: Sage, 1994.

9. Caprara GV, Barbaranelli C, Steca P, Malone PS. Teachers' self efficacy beliefs as determinants of jobs satisfaction and students' academic achievement: a study at the school level. J Sch Psychol 2006;44:473-90.

10. Ross JA. The antecedents and consequences of teacher efficacy. Adv Res Teach 1998;7:49-73.

11. Shek DTL. Effectiveness of the Tier 1 Program of Project P.A.T.H.S.: findings based on the first 2 years of program implementation. ScientificWorldJournal 2009;9:539-47.
12. Shek DTL. Special issue: evaluation of Project P.A.T.H.S. in Hong Kong. ScientificWorldJournal: TSW Holist Health Med 2008;8:1-94.

13. Shek DTL. Using students' weekly diaries to evaluate positive youth development programs: a case of Project P.A.T.H.S. in Hong Kong. Adolescence 2009;44:69-85.

14. Shek DTL, Ma HK, Sun RCF. Interim evaluation of the Tier 1 Program (Secondary 1 Curriculum) of the Project P.A.T.H.S.: first year of the Full Implementation Phase. ScientificWorldJournal: TSW Holist Health Med 2008;8:47-60.

15. Shek DTL, Ng CSM. Qualitative evaluation of the Project P.A.T.H.S.: findings based on focus groups with student participants. ScientificWorldJournal: Child Health Hum Dev 2009;9:691-703.

16. Shek DTL, Sun RCF, Siu AMH. Interim evaluation of the Secondary 2 Program of Project P.A.T.H.S.: insights based on the Experimental Implementation Phase. ScientificWorldJournal: TSW Holist Health Med 2008;8:61-72.

17. Herzog RJ. Teaching what you practice: the need for selfreflection in academic settings. J Public Aff Educ 2004;3:225-32.

18. Larrivee B. Transforming teaching practice: becoming the critically reflective teacher. Ref Pract 2000;1:293-307.

19. Hanson J. Should your lips be zipped? How therapist self-disclosure and non-disclosure affects clients. Couns Psychother Res 2005;5:96-104.

20. Goldstein GS, Benassi VA. The relation between teacher selfdisclosure and student classroom participation. Teach Psychol 1994;21:212-7.

21. Shek DTL, Sun RCF. Implementation of a positive youth development program in a Chinese context: the role of policy, program, people, process, and place. ScientificWorldJournal 2008;8:960-6.

22. Herzberg F. One more time: how do you motivate employees? Harvard Business Rev 1968;46:53-62.

23. Egan LC, Santos LR, Bloom P. The origins of cognitive dissonance: evidence from children and monkeys. Psychol Sci 2007; 18:978-83.

24. Shek DTL, Sun RCF. Subjective outcome evaluation of the Project P.A.T.H.S.: qualitative findings based on the experiences of program implementers. ScientificWorldJournal 2007;7:102435.

25. Shek DTL, Lee TY. Qualitative evaluation of the Project P.A.T.H.S.: findings based on focus groups with student participants. Int J Adolesc Med Health 2008;20:449-62.

26. Shek DTL, Sun RC, Siu AMH. Interim evaluation of the Secondary 2 Program of Project P.A.T.H.S.: Insights based on the Experimental Implementation Phase. ScientificWorldJournal 2008;8:61-72.

27. Shek DTL, Sun RCF, Lam CM, Lung DWM, Lo SC. Evaluation of Project P.A.T.H.S. in Hong Kong: utilization of student weekly dairy. ScientificWorldJournal 2008;8:13-21.

28. Shek DTL, Sun RCF. Implementation of a positive youth development program in a Chinese context: the role of policy, program, people, process, and place. ScientificWorldJournal 2008; 8:960-96. 